\title{
Decision-Making Strategy for the Treatment of Rheumatoid Arthritis-Associated Interstitial Lung Disease (RA-ILD)
}

\author{
Hideaki Yamakawa ${ }^{1,2, *(D)}$, Takashi Ogura ${ }^{3}$, Hideto Kameda ${ }^{4}$, Tomoo Kishaba ${ }^{5}$ (D) , Tae Iwasawa ${ }^{6}$, \\ Tamiko Takemura ${ }^{7}$ and Kazuyoshi Kuwano ${ }^{2}$ \\ 1 Department of Respiratory Medicine, Saitama Red Cross Hospital, 1-5 Shintoshin, Chuo-ku, \\ Saitama 330-8553, Japan \\ 2 Department of Internal Medicine, Division of Respiratory Diseases, The Jikei University School of Medicine, \\ 3-25-8 Nishi-Shinbashi, Minato-ku, Tokyo 105-8461, Japan; kkuwano@jikei.ac.jp \\ 3 Department of Respiratory Medicine, Kanagawa Cardiovascular and Respiratory Center, \\ 6-16-1 Tomioka-higashi, Kanazawa-ku, Yokohama 236-0051, Japan; ogura@kanagawa-junko.jp \\ 4 Department of Internal Medicine, Division of Rheumatology, Faculty of Medicine, Toho University, \\ 2-22-36 Ohashi, Meguro-ku, Tokyo 153-8515, Japan; hideto.kameda@med.toho-u.ac.jp \\ 5 Department of Respiratory Medicine, Okinawa Chubu Hospital, Okinawa, 81 Miyazato, \\ Uruma 904-2293, Japan; kishabatomoo@gmail.com \\ 6 Department of Radiology, Kanagawa Cardiovascular and Respiratory Center, 6-16-1 Tomioka-higashi, \\ Kanazawa-ku, Yokohama 236-0051, Japan; tae_i_md@wb3.so-net.ne.jp \\ 7 Department of Pathology, Kanagawa Cardiovascular and Respiratory Center, 6-16-1 Tomioka-higashi, \\ Kanazawa-ku, Yokohama 236-0051, Japan; tamikobyori@gmail.com \\ * Correspondence: hide1144@jikei.ac.jp
}

check for updates

Citation: Yamakawa, H.; Ogura, T.; Kameda, H.; Kishaba, T.; Iwasawa, T.; Takemura, T.; Kuwano, K.

Decision-Making Strategy for the Treatment of Rheumatoid Arthritis-Associated Interstitial Lung Disease (RA-ILD). J. Clin. Med. 2021, 10, 3806. https://doi.org/10.3390/ jcm10173806

Academic Editor: Chang-Hee Suh

Received: 30 June 2021

Accepted: 23 August 2021

Published: 25 August 2021

Publisher's Note: MDPI stays neutral with regard to jurisdictional claims in published maps and institutional affiliations.

Copyright: (c) 2021 by the authors. Licensee MDPI, Basel, Switzerland. This article is an open access article distributed under the terms and conditions of the Creative Commons Attribution (CC BY) license (https:/ / creativecommons.org/licenses/by/ $4.0 /)$.

\begin{abstract}
Rheumatoid arthritis (RA) is a common type of autoimmune arthritis. Patient clinical outcomes might be influenced by numerous respiratory diseases, but interstitial lung disease (ILD) is the most important comorbidity. RA-associated ILD (RA-ILD) is divided into acute/subacute and chronic forms. In the acute/subacute course, if the disease is severe as indicated by a diffuse alveolar damage pattern, high-dose corticosteroids combined with antimicrobial agents should be promptly initiated while considering the differential diagnoses, primarily acute exacerbation (AE) of RA-ILD, drug-induced pneumonitis, and Pneumocystis pneumonia. As initial therapeutic management in the chronic course, the RA itself should be stabilized without delay; thereafter, the activity of ILD itself can be stabilized, considering the safety of each anti-rheumatic drug. The formation of the usual interstitial pneumonia (UIP) pattern is the most important determinant because lung function can worsen more quickly with this pattern. However, because clinicians can fail to identify specific radiological patterns, it is important to determine whether each patient with RA-ILD has UIP-like lesions such as subpleural reticulation, traction bronchiectasis, and honeycombing especially progressively enlarged cysts. In patients with progressive RA-ILD and high risk for infection or AE of ILD in whom fibrosis is dominant, clinicians should consider starting an anti-fibrotic agent.
\end{abstract}

Keywords: antifibrotic agents; DMARDs; interstitial lung disease; rheumatoid arthritis; therapy

\section{Introduction}

Rheumatoid arthritis (RA) is a systemic inflammatory disease with a prevalence of approximately $0.5-1.0 \%$ in the general population [1]. The prevalence of RA-associated interstitial lung disease (RA-ILD) ranges widely in the literature, likely due to varying methodologies used in its detection. Some studies identified RA-ILD through clinical detection, with prevalence estimates ranging from 2 to $8 \%$ in RA patients [2]. The most common reasons for death in RA patients in Japan are both respiratory disease and malignancy [3]. Among the respiratory diseases, ILD is the most predominant manifestation, and serious morbidity and increased mortality can be expected in some patients with RA-ILD [3,4]. Interestingly, a recent report showed that patients with RA-ILD are also at increased risk 
for cancer mortality [5]. Compared with RA without ILD, RA-ILD was clearly associated with poor prognosis [3-5]. Clinical physicians should thus recognize that the management of RA-ILD affects the prognosis of RA patients because ILD is a frequent manifestation and a poor prognostic factor in RA. The present review aimed to assess the characteristics of RA-ILD through an overview of previous studies in this field and then focus on the future treatment of RA-ILD.

\section{Important Points in the Management of RA-ILD}

Initially, clinicians should confirm whether the onset of RA-ILD is of the acute/subacute or chronic type, after which they can carefully discriminate among the wide variety of differential diagnoses. If patients present with an acute/subacute disease course, their life can be at risk even if the abnormalities on chest high-resolution computed tomography (HRCT) appear to be mild. In contrast, in patients with the chronic form of RA-ILD, clinicians should evaluate the activity of both arthritis and ILD and try to detect the early phase of an acute exacerbation (AE) of ILD, infection, and malignancy as soon as possible because these factors are associated with death in these patients [5].

\section{Acute/Subacute Course of RA-ILD}

This section may be divided into subheadings. It should provide a concise and precise description of the experimental results, their interpretation, as well as the experimental conclusions that can be drawn.

\subsection{Diagnostic Assessment}

The acute/subacute course of RA-ILD presents patterns of organizing pneumonia $(\mathrm{OP})$ and diffuse alveolar damage (DAD). The OP pattern is suspected in cases refractory to antimicrobial drugs or that show wandering shadows, and almost all cases of this pattern resolve with a low to medium dose of corticosteroid therapy or even resolve spontaneously, which leads to a favorable prognosis [6].

When acute respiratory failure is accompanied by a wide range of pulmonary shadows radiographically, RA associated with diffuse alveolar damage (RA-DAD) needs to be distinguished from a variety of etiologies [6,7]. If the possibility of acute cardiac failure can be excluded, three major differential diagnoses are possible: pulmonary infection, RA-ILD itself (i.e., RA-DAD), and drug-induced pneumonia. If previous chest HRCT images are available, the clinician can confirm whether the patient has had RA-ILD from the beginning. Because most cases of RA-DAD are an AE of existing RA-ILD, RA-DAD is of low priority if the patient has no existing ILD [7]. Next to anticancer drugs, RA drugs such as methotrexate (MTX) and leflunomide can cause drug-induced pneumonitis, and Pneumocystis pneumonia (PCP) with RA is a well-known pulmonary infection that is sometimes encountered during treatment with RA drugs, particularly MTX and biologics [8-12]. For example, differentiating acute respiratory failure caused by MTX-induced pneumonitis from PCP and AE of RA-ILD is not always easy because these three clinical entities might present similar HRCT findings. Therefore, clinicians should consult the pharmaceutical information on RA drugs.

\subsection{Therapeutic Assessment of Acute/Subacute RA-ILD Showing a Wide Variety of Bilateral Pulmonary Shadows}

Several steps need to be taken in the assessment of acute/subacute RA-ILD. First, if the possibility of drug-induced pneumonitis exists, the drugs treating RA should be stopped promptly based on consideration of the balance between RA activity and respiratory status [13]. See the flow chart in Figure 1. 
Acute/subacute course with wide range of bilateral pulmonary shadows in RA-ILD

Exclude acute heart failure

*If the possibility for drug-induced pneumonitis exists, these drugs should be promptly stopped.

** Judge severity in reference to the degree of respiratory failure and pulmonary shadows.

***Possibility of DAD?

No Antibiotics for bacterial pneumonia or TMP/SMX for PCP are started.

If drug-induced pneumonitis is suspected, these drugs are stopped, and careful observation is needed.

High-dose corticosteroids in combination with the above broad-spectrum antimicrobial agents should be promptly initiated in patients without waiting for the results of various tests such as $\beta \mathrm{D}$-glucan or Pneumocystis jirovecii PCR testing of a respiratory specimen.

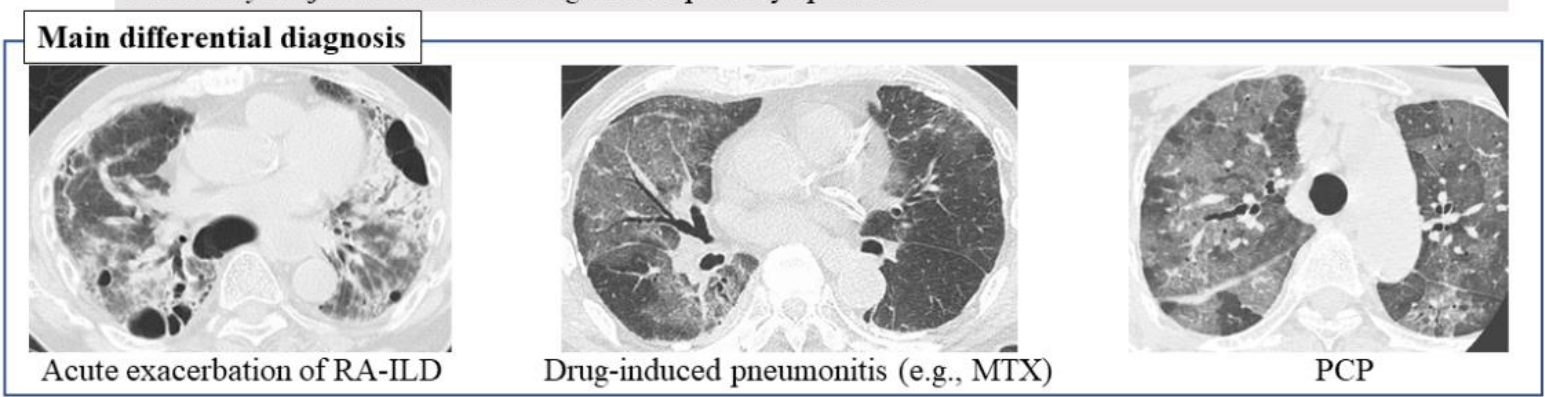

Figure 1. Three differential diagnoses of the acute/subacute course of RA-ILD are acute exacerbation of RAILD, drug-induced pneumonitis, and PCP. Abbreviations: DAD = diffuse alveolar damage; MTX = methotrexate; $\mathrm{PCP}=$ Pneumocystis pneumonia; RA-ILD = rheumatoid arthritis-associated interstitial lung disease; TMP /SMX = trimethoprim/sulfamethoxazole. Flow chart. First *, if the possibility of drug-induced pneumonitis exists, the drugs treating RA should be stopped promptly. Second, clinicians should judge severity ** and the possibility of DAD ${ }^{* * *}$. Three differential diagnoses of the acute/subacute course of RA-ILD are acute exacerbation of RA-ILD, drug-induced pneumonitis, and PCP.

Second, the severity of pulmonary disease, which is indicated by the degree of respiratory failure and pulmonary shadows present and whether a DAD pattern is observed, needs to be assessed in each patient with RA-ILD. Considering that the pattern appears as mild pulmonary shadows in the patient in respiratory failure, a DAD pattern may be possible. In the radiological pattern of DAD shown by HRCT, heterogeneous foci of consolidation and ground-glass opacity (GGO) with a gravitationally dependent gradient are present along with increased consolidation in the posterobasal portions of the lungs [14]. A diffuse "crazy-paving" pattern can also be seen [14]. With organization and fibrosis, reticulation and traction bronchiectasis may develop, which often shows an anterior predominance.

Third, in cases with mild severity and an infectious clinical scenario, antibiotics to treat bacterial pneumonia and first-line therapy with trimethoprim/sulfamethoxazole (TMP/SMX) for PCP have likely already been started [15]. If drug-induced pneumonitis is suspected, causative drugs are stopped and careful observation is begun. However, in the case of high severity, as suggested by the presence of $\mathrm{DAD}$, high-dose corticosteroids in combination with broad-spectrum antimicrobial agents including TMP/SMX should be promptly initiated without waiting for the results of tests such as $\beta \mathrm{D}$-glucan or PCR for Pneumocystis jirovecii in respiratory specimens [15]. Although the efficacy of this therapy is uncertain in the case of AE of RA-ILD, severe PCP and drug-induced pneumonitis such as that induced by MTX may be improved by high-dose corticosteroid administration $[15,16]$. If the response to corticosteroid therapy is poor, the administration of other immunosuppressive agents such as cyclophosphamide (CYC), cyclosporine A, and tacrolimus should be considered, which has the potential to improve the prognosis of the AE of RA-ILD [17]. The presence of AE of RA-ILD indicates an extremely poor condition with high mortality $(64 \%)[2,4,5]$, and thus, this serious condition needs to be carefully considered. 


\section{Chronic Course of RA-ILD}

\subsection{Prevalence and Clinical Manifestations}

A significant percentage of patients have ILD either predating $(10 \%)$ or concomitant with $(17 \%)$ the diagnosis of RA. About half of the patients develop ILD either before or within 5 years of the RA diagnosis [18]. Some studies identified prevalence estimates ranging from 2 to $8 \%$ in RA patients [2], whereas the estimated prevalence based on HRCT analysis is reported at a relatively higher range of 27-67\% [19-27]. Most cases are diagnosed as being asymptomatic, with 7-29\% having clinical symptoms [24-27]. Although the true prevalence of ILD in RA has not been established, importantly, clinically evident ILD may occur in approximately $10 \%$ of RA patients [19-28].

\subsection{Disease Behavior}

In 2017, Zamora-Legoff et al. reported that over a 5-year period after the diagnosis of RA-ILD (3.3-year median follow-up time from ILD diagnosis), $40 \%$ of patients developed a diffusing capacity for carbon monoxide (DLCO) of $<40 \%$ predicted and $22 \%$ developed a forced vital capacity (FVC) of $<50 \%$ predicted, which indicated severe restrictive disorder, and a third of the patients required supplemental oxygen [29]. Of the patients without respiratory restriction at the initial diagnosis, about $10 \%$ of them had developed severe restrictive disorder over the 5 years [29]. Mena-Vázquez et al. reported in 2021 that 19.8\% of RA-ILD patients had experienced progression (worsening of FVC of $>10 \%$ or DLCO of $>15 \%$ and radiological progression) over the 5 years from their ILD diagnosis [30]. These patients were classified as having progressive fibrosing ILD (PF-ILD) [31,32]. Although presently there are only a few reports of ILD disease progression, which vary based on the detection methods used, taken together, at least $10 \%$ of RA-ILD patients might experience progression over the long-term course of the disease.

\subsection{Predictors of ILD Progression and Prognostic Factors}

The independent predictors of worsening of RA-ILD were reported to be the usual interstitial pneumonia (UIP) pattern, lowered FVC (e.g., $<80 \%$ ), cigarette smoking, and higher anticitrullinated protein antibody titers $[20,25,30,33]$. Mena-Vázquez et al. reported that treatment with abatacept (ABT) as a synthetic analog of CTLA-4Ig, tocilizumab (TCZ) as an interleukin-6 inhibitor (IL-6i), and rituximab (RTX) as an anti-CD20 chimeric antibody was associated with predictors of stabilized pulmonary function [30]. Factors significantly related to mortality in RA were male sex, older age, having ILD, and higher articular activity [5]. Poor prognostic factors in RA-ILD include male sex, older age, lower FVC and DLCO, deterioration in FVC and DLco over 6 months, wide areas of pulmonary fibrosis, UIP pattern, and honeycombing [4,7,34-38].

\subsection{Prognosis and Causes of Death Compared with Idiopathic Pulmonary Fibrosis}

Previous large cohort studies reported that median survival after the diagnosis of RA-ILD was only 2.6-3.0 years with a 5-year survival rate of 35-39\%, similar to that for idiopathic pulmonary fibrosis (IPF) [4,39]. In fact, RA-ILD has also been reported to be associated with IPF-related genes: MUC5B promoter variant and leukocyte telomere length $[40,41]$. In particular, the prognosis of RA-ILD patients with a UIP pattern, as with that of IPF, was poorer than the prognosis of patients with a non-UIP pattern $[4,7,22,28]$. However, prognosis in RA-ILD varied across the reports (median survival for RA-UIP of 3.2-10.2 years and RA-nonspecific interstitial pneumonia [NSIP] of 7.8-17 years) (Table 1 , Figure 2), with recent reports showing that survival for RA-ILD with a UIP pattern was significantly better than that for IPF [37,42-47]. Figure 3 depicts a case with a stable course of RA-UIP with honeycombing in which the fibrotic area does not really deteriorate over 5 years. The reason for the different results regarding prognosis may be explained by the following three points. 
Table 1. HRCT patterns and prognosis of RA-ILD.

\begin{tabular}{|c|c|c|c|c|c|c|}
\hline Authors & Year & $\begin{array}{l}\text { No. of } \\
\text { Patients }\end{array}$ & HRCT Patterns & $\begin{array}{l}\text { Reference to } \\
\text { Criteria of } \\
\text { HRCT } \\
\text { Classification }\end{array}$ & $\begin{array}{c}\text { 5-Year Survival Rate } \\
(\%)\end{array}$ & $\begin{array}{l}\text { Median } \\
\text { Survival }\end{array}$ \\
\hline Kim et al. [23] & 2010 & 82 & $\begin{array}{c}24 \% \text { (UIP) } \\
23 \% \text { (NSIP) } \\
51 \% \\
\text { (Indeterminate) } \\
\text { 2\% (Others) }\end{array}$ & $\begin{array}{l}2002 \text { ATS/ERS } \\
\text { classification of } \\
\text { the IIPs }\end{array}$ & $\mathrm{N} / \mathrm{A}$ & $\begin{array}{c}3.2 \text { years }(\mathrm{UIP}) \\
6.6 \text { years } \\
(\text { Non-UIP) }\end{array}$ \\
\hline $\begin{array}{c}\text { Tsuchiya et al. } \\
\text { [42] }\end{array}$ & 2011 & 94 & $\begin{array}{c}61 \% \text { (UIP) } \\
17 \% \text { (NSIP) } \\
22 \% \text { (Others) } \\
65 \% \text { (UIP) }\end{array}$ & $\begin{array}{l}2002 \text { ATS/ERS } \\
\text { classification of } \\
\text { the IIPs }\end{array}$ & $\begin{array}{c}36.6 \%(\mathrm{UIP}) \\
93.8 \% \text { (NSIP) }\end{array}$ & $\begin{array}{l}3.9 \text { years }(\mathrm{UIP}) \\
17 \text { years }(\mathrm{NSIP})\end{array}$ \\
\hline Kelly et al. [25] & 2014 & 230 & $\begin{array}{c}24 \% \text { (NSIP) } \\
11 \% \text { (Others) }\end{array}$ & $\mathrm{N} / \mathrm{A}$ & $\mathrm{N} / \mathrm{A}$ & $\mathrm{N} / \mathrm{A}$ \\
\hline $\begin{array}{l}\text { Solomon et al. } \\
\text { [26] }\end{array}$ & 2016 & 137 & $\begin{array}{l}\text { 79\% (Definite + } \\
\text { Possible UIP) } 21 \% \\
\text { (NSIP) }\end{array}$ & $\begin{array}{l}2011 \text { IPF } \\
\text { guideline }\end{array}$ & $\mathrm{N} / \mathrm{A}$ & $\begin{array}{c}10.2 \text { years (Defi- } \\
\text { nite+Possible } \\
\text { UIP) } \\
\text { 13.6 years } \\
\text { (NSIP) }\end{array}$ \\
\hline $\begin{array}{c}\text { Morisset et al. } \\
\text { [43] }\end{array}$ & 2017 & 309 & $\begin{array}{c}24 \% \text { (Definite UIP) } \\
\text { 16\% (Possible UIP) } \\
\text { 60\% (Inconsistent } \\
\text { with UIP) }\end{array}$ & $\begin{array}{l}2011 \text { IPF } \\
\text { guideline }\end{array}$ & $\mathrm{N} / \mathrm{A}$ & $\mathrm{N} / \mathrm{A}$ \\
\hline $\begin{array}{l}\text { Zamora-Legoff } \\
\text { et al. [20] }\end{array}$ & 2017 & 181 & $\begin{array}{c}54 \%(\mathrm{UIP}) \\
40 \%(\mathrm{NSIP}) \\
6 \%(\mathrm{OP})\end{array}$ & $\mathrm{N} / \mathrm{A}$ & $\begin{array}{c}55.2 \%(\mathrm{UIP}) \\
65.0 \%(\mathrm{NSIP}) \\
47.4 \%(\mathrm{OP})\end{array}$ & $\mathrm{N} / \mathrm{A}$ \\
\hline Yunt et al. [44] & 2017 & 158 & $\begin{array}{c}63 \% \text { (Definite UIP) } \\
15 \% \text { (Possible UIP) } \\
22 \% \text { (NSIP) }\end{array}$ & $\begin{array}{l}2011 \text { IPF } \\
\text { guideline }\end{array}$ & $\mathrm{N} / \mathrm{A}$ & $\begin{array}{c}8.3 \text { years } \\
\text { (Definite UIP) } \\
6.1 \text { years } \\
\text { (Possible UIP) } \\
\text { Incalculable } \\
\text { (NSIP) }\end{array}$ \\
\hline Fu et al. [45] & 2019 & 266 & $\begin{array}{c}\text { 17\% (Definite UIP) } \\
20 \% \text { (Possible UIP) } \\
32 \% \\
\text { (Unclassifiable) } \\
30 \% \text { (Others) }\end{array}$ & $\begin{array}{l}2011 \text { IPF } \\
\text { guideline }\end{array}$ & $69.7 \%$ (All) & $\mathrm{N} / \mathrm{A}$ \\
\hline Jacob et al. [46] & 2019 & 157 & $\begin{array}{c}35 \% \text { (Definite UIP) } \\
\text { 36\% (Probable UIP) } \\
\text { 29\% (Inconsistent } \\
\text { with UIP) }\end{array}$ & $\begin{array}{l}2018 \text { Diagnostic } \\
\text { criteria for IPF: } \\
\text { Fleischner } \\
\text { Society }\end{array}$ & $\begin{array}{c}<6 \text {-year survival } \\
\text { rate }> \\
45 \% \text { (Definite UIP) } \\
58 \% \text { (Probable UIP) }\end{array}$ & $\mathrm{N} / \mathrm{A}$ \\
\hline $\begin{array}{c}\text { Yamakawa et al. } \\
\text { [47] }\end{array}$ & 2019 & 112 & $\begin{array}{c}21 \% \text { (Definite UIP) } \\
20 \% \text { (Probable UIP) } \\
27 \% \text { (Mixed } \\
\text { NSIP/UIP) } \\
29 \% \text { (Alternative) }\end{array}$ & $\begin{array}{l}2018 \text { IPF } \\
\text { guideline }\end{array}$ & $\begin{array}{c}70.2 \% \text { (Definite UIP) } \\
90.9 \% \text { (Probable UIP) } \\
\text { 80.0\% (Mixed } \\
\text { NSIP /UIP) } \\
90.0 \%(\mathrm{NSIP})\end{array}$ & $\begin{array}{c}6.8 \text { years } \\
\text { (Definite UIP) } \\
9.1 \text { years } \\
\text { (Probable UIP) } \\
\text { 8.6 years } \\
\text { (Mixed } \\
\text { NSIP/UIP) } \\
\text { 7.8 years (NSIP) }\end{array}$ \\
\hline Kakutani et al. [5] & 2020 & 261 & $\begin{array}{c}46 \% \text { (Definite + } \\
\text { Possible UIP) } \\
54 \% \text { (Non-UIP) }\end{array}$ & $\begin{array}{l}2011 \text { IPF } \\
\text { guideline }\end{array}$ & $\mathrm{N} / \mathrm{A}$ & $\mathrm{N} / \mathrm{A}$ \\
\hline
\end{tabular}

Abbreviations: ATS = American Thoracic Society; ERS = European Respiratory Society; HRCT = high-resolution computed tomography; $\mathrm{IPF}=$ idiopathic pulmonary fibrosis; NSIP = nonspecific interstitial pneumonia; OP = organizing pneumonia; RA-ILD = rheumatoid arthritis-associated interstitial lung disease; UIP = usual interstitial pneumonia. 


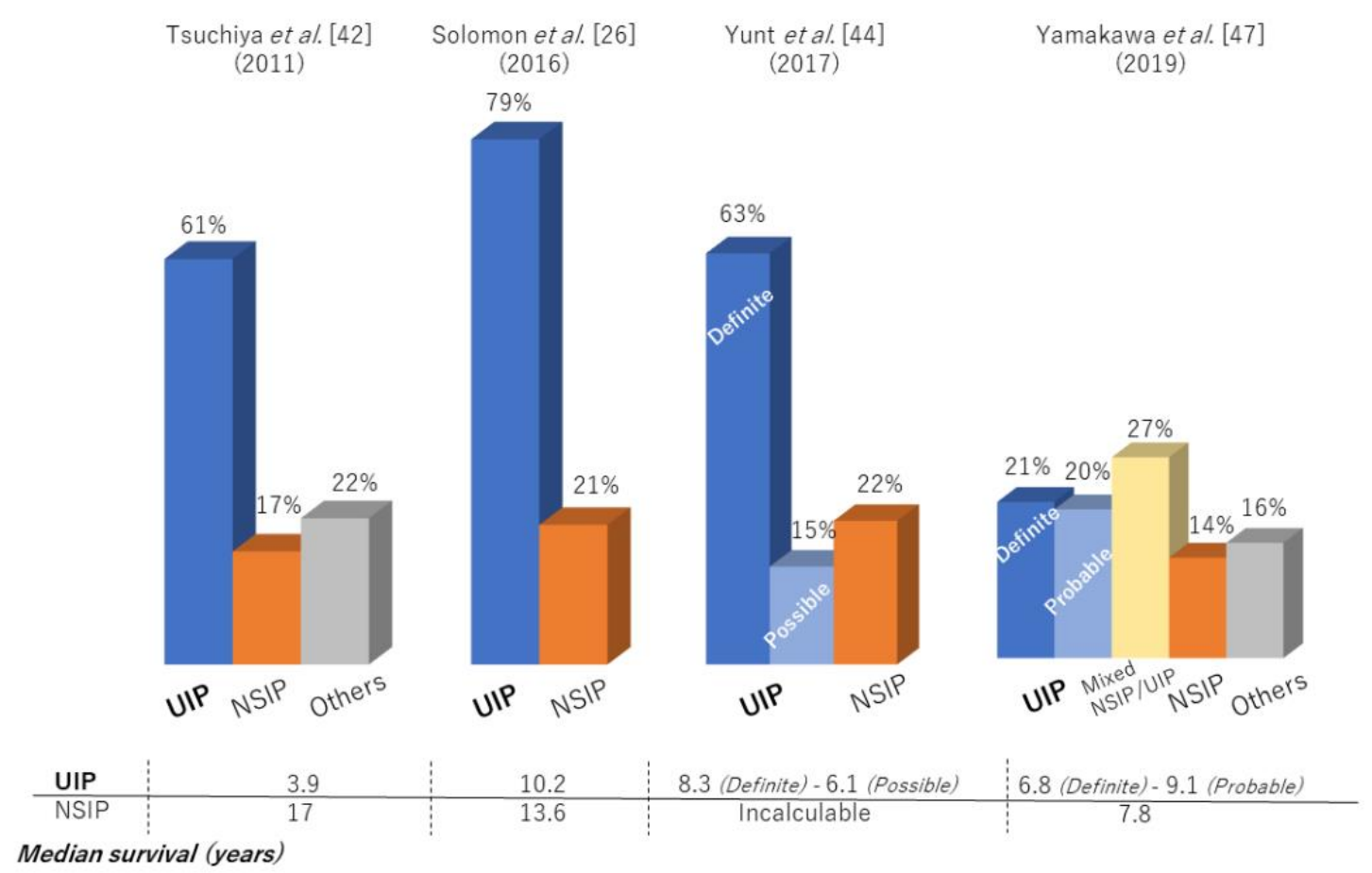

Figure 2. High-resolution computed tomography patterns and median survival of patients with RA-ILD.

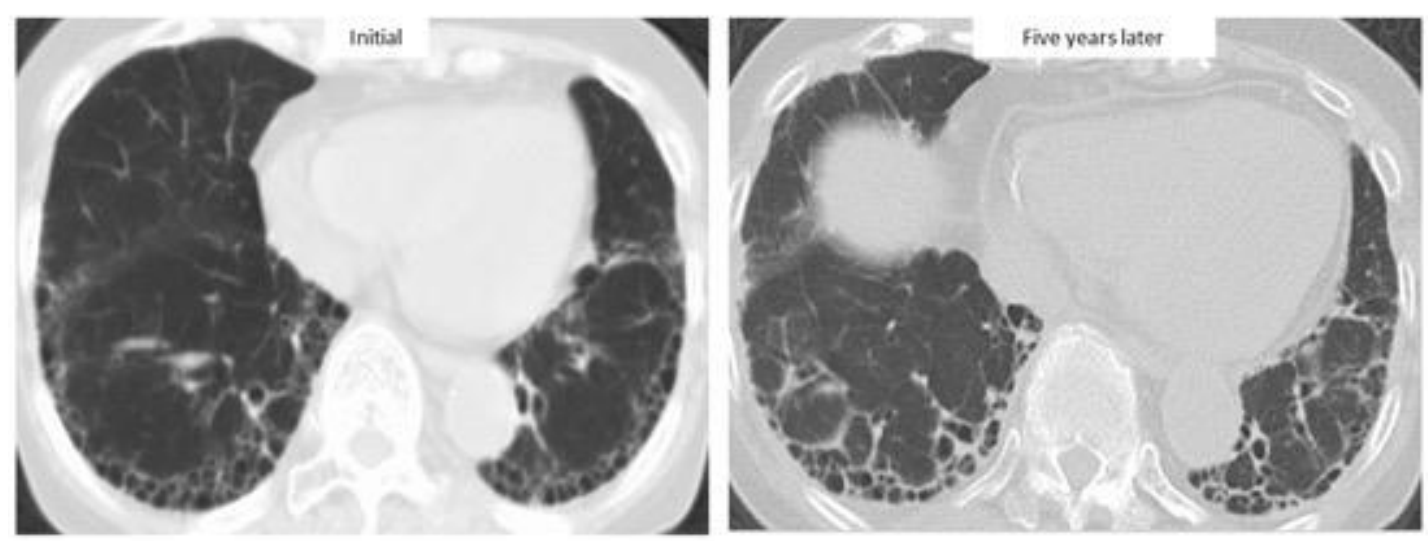

Figure 3. High-resolution computed tomographic images of a patient with a stable course of RA-ILD for five years.

1: Sample bias in the diagnosis of RA-ILD, as this depends on whether a respiratory or rheumatology physician made the diagnosis. Many patients were diagnosed by rheumatologists as not having respiratory symptoms, whereas most respiratory physicians often find that RA patients have progressive ILD and/or respiratory symptoms in clinical practice $[26,42,43,47]$.

2: Differences in the methods of analyzing or in the analysts who assess the HRCT pattern. In accordance with the times, classification guidelines for idiopathic interstitial pneumonia and IPF are often used, and most patients are classified as having different subtypes (e.g., UIP, NSIP) based on HRCT. However, an overlapping or indeterminate pattern (i.e., an unclassifiable pattern other than UIP, NSIP, or OP) is present to some extent in 6 to $52 \%$ of the RA-ILD population because connective tissue disease-associated ILD presents a diversity of patterns [23,47-49]. Therefore, we often cannot classify an HRCT pattern specifically as either UIP or NSIP in clinical practice as shown in Figure 4. Thus, the correlation between HRCT pattern and prognosis can vary. 


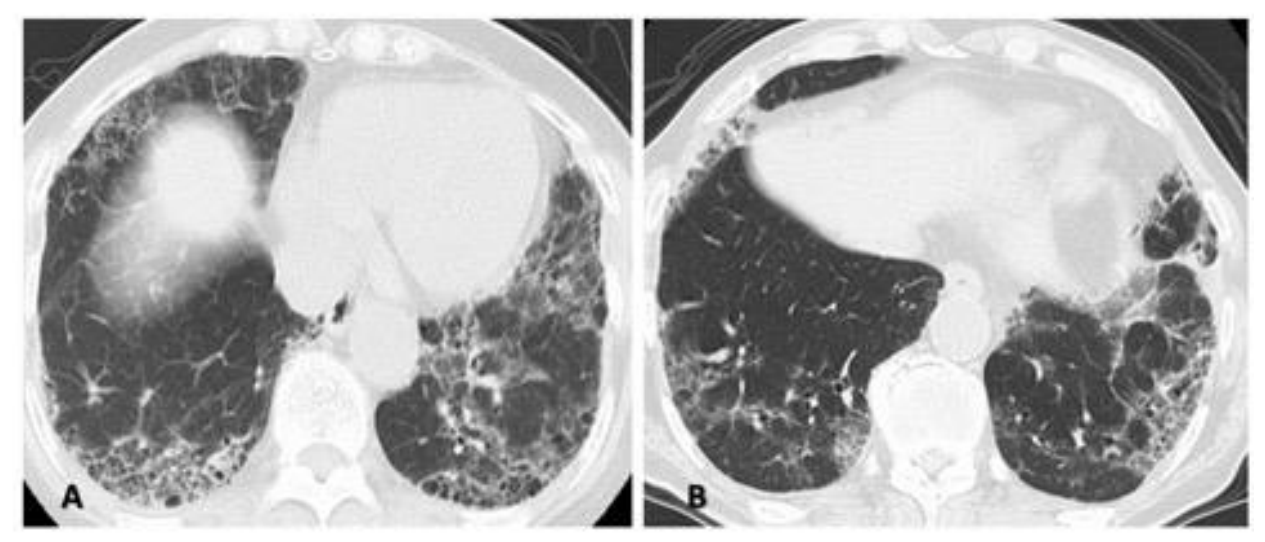

Figure 4. Two cases illustrating the difficulty of classifying a specific high-resolution computed tomography pattern as a mixed NSIP/UIP pattern. Both central or diffuse distribution of reticulation or ground-glass opacity as the component of NSIP and subpleural reticulations with or without honeycombing as the component of UIP in the lower lung are shown. (A) A 71-year-old woman and (B) a 72-year-old man. Abbreviations: NSIP = nonspecific interstitial pneumonia; UIP = usual interstitial pneumonia.

3: Infection including pneumonia is the more frequent cause of death rather than IPF. The most common causes of death in RA patients were malignancy $(24 \%)$, cardiovascular disorder $(14 \%)$, infectious pneumonia $(12 \%)$, and ILD $(11 \%)$ as reported by Nakajima et al. [50]. Regardless of whether the etiology was IPF or RA-ILD, three major reasons for the cause of death were AE of ILD (IPF: 40-46\%, RA-ILD: 20-31\%), chronic progression (IPF: 22-24\%, RA-ILD: 18-24\%), and lung cancer (IPF: 8-11\%, RA-ILD: 8-10\%) (Figure 5) [3,5,42,47,50-52]. The frequency of infectious pneumonia as a cause of death is somewhat higher in RA-ILD versus IPF (12-18.6\% vs. 7-12\%). Patients with RA have elevated susceptibility to serious infections due to features of the disease itself, comorbidities, and immunosuppressive treatment $[2,5,28]$. In other words, the prognosis in patients with RA-ILD may improve if clinicians can control any infectious complications well.
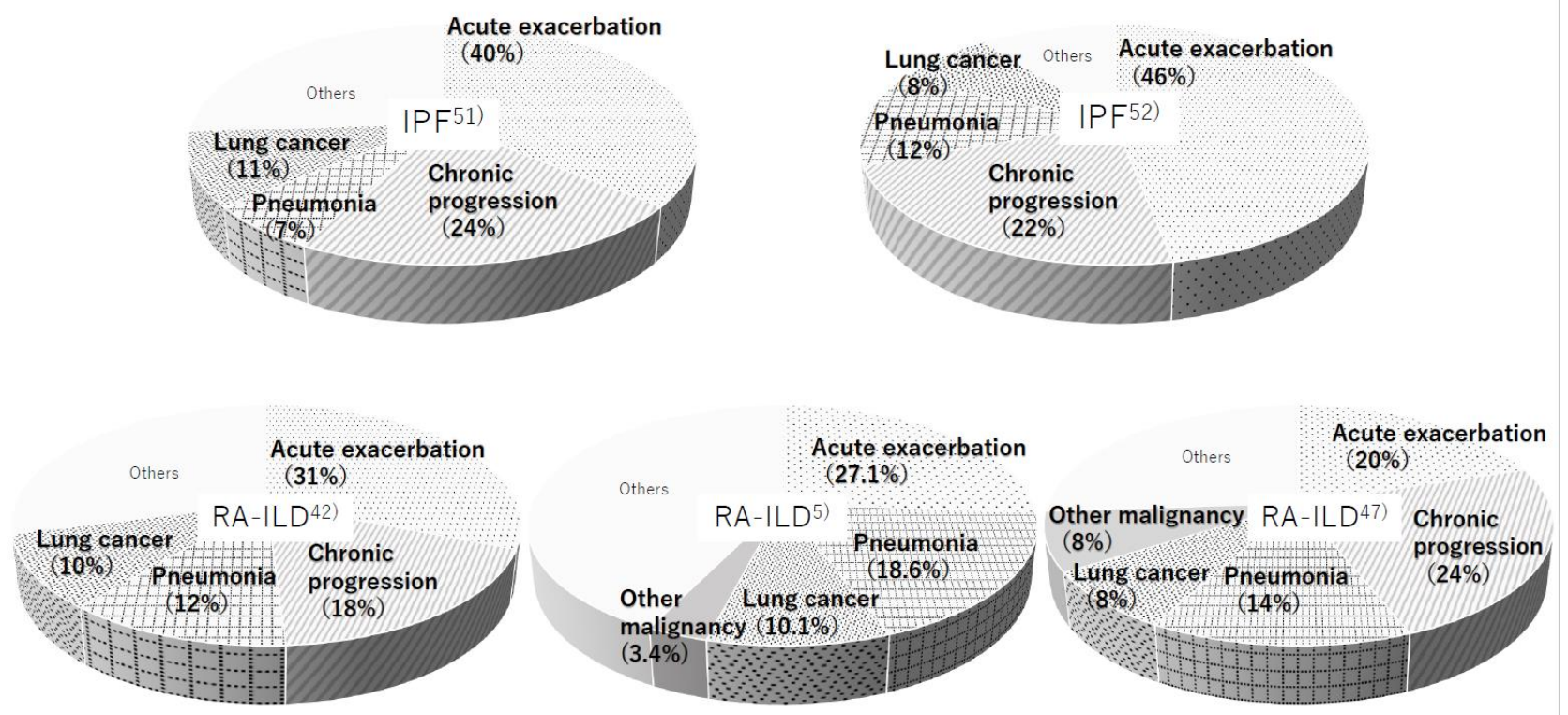

Figure 5. Causes of death were reported by five different studies in patients with idiopathic pulmonary fibrosis (IPF) (upper row) and RA-ILD (lower row). 
Taken together, the first important thing when determining treatment is not only to clearly judge whether the patient shows a UIP pattern or non-UIP pattern, such as an NSIP pattern, but also whether each patient with RA-ILD has UIP-like lesions (i.e., subpleural reticulation with traction bronchiectasis, honeycombing) because HRCT can often fail to correctly identify patterns such as UIP, NSIP, and unclassifiable [53]. Although not all RA-UIP shows a progressive course, clinicians should consider the possibility that patients will develop progressive ILD if they have UIP-like lesions at the time of diagnosis (Figure 6, upper row) [53]. Of note, even though the initial HRCT pattern might be one of NSIP, UIPlike lesions can become apparent and then progress to ILD (Figure 6, lower row) [36,53,54]. The second important thing in the management of RA-ILD is the prevention and early detection of infectious complications including pneumonia $[3,5,28]$. In addition, for RA-ILD patients to have a better prognosis than that for IPF, early detection of malignancy may be essential for those who are male or smokers [5].

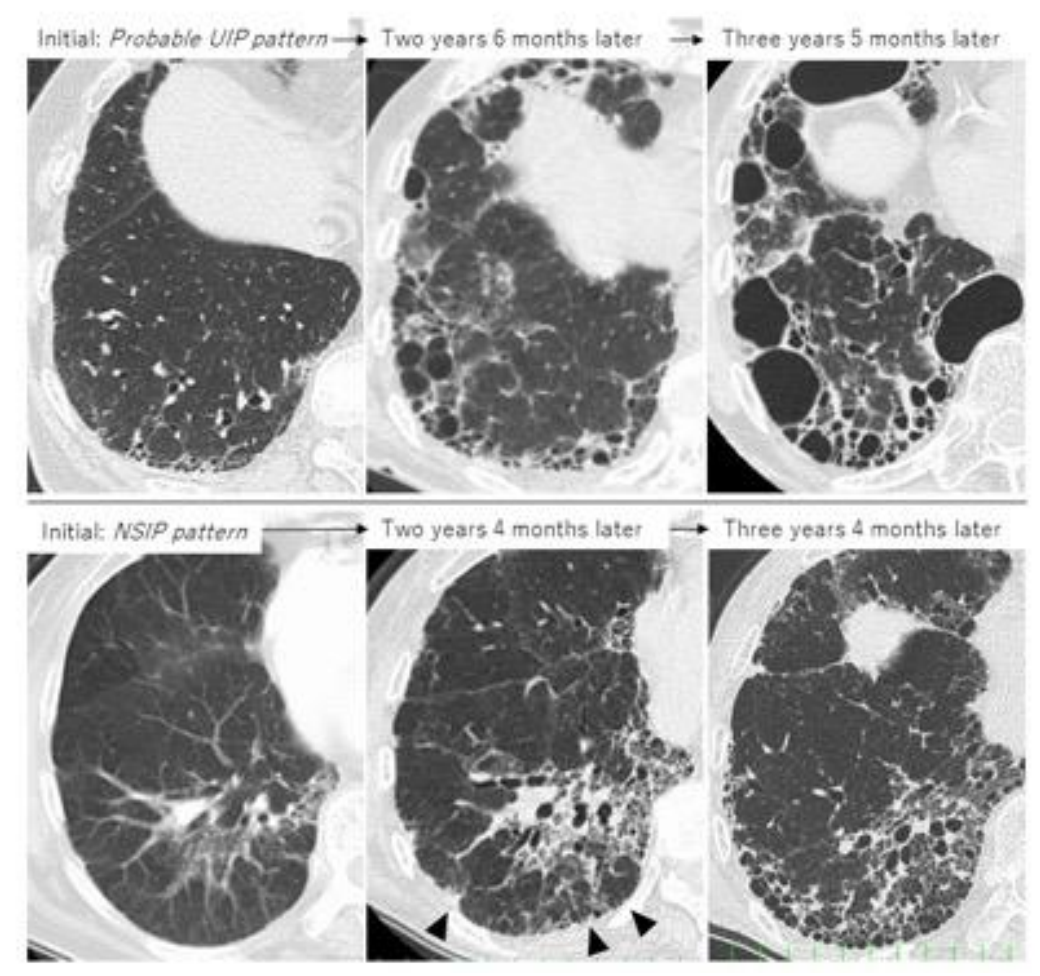

Figure 6. Two cases of progressive RA-ILD showing the evolution of honeycombing during followup. Upper row: probable UIP pattern at initial imaging; lower row: NSIP pattern at initial imaging (arrowhead indicates UIP-like lesion formation as subpleural reticulation).

\subsection{Therapeutic Assessment of the Chronic Course of RA-ILD}

The therapeutic assessment of RA-ILD is difficult due to the lack of evidence and can be controversial $[2,46,52]$. Two main factors are important in the decision to start treatment: judging whether A) arthritis itself is controllable and B) the patient has progressive ILD (see the flow chart in Figure 7) [55-57]. Although the judgment of the latter can be difficult, the concept and definition of PF-ILD, which includes RA-ILD, were created in the INBUILD trial and are also useful in clinical practice [31]. The definition is based on the progression of fibrosis as assessed by FVC and HRCT findings and worsening of respiratory symptoms at a certain rate or even faster [31]. Based on this definition, Cottin et al. proposed that the criteria for PF-ILD include a relative decline of $\geq 10 \%$ in FVC; a relative decline of $\geq 15 \%$ in DLCO; or worsening symptoms or a worsening radiological appearance accompanied by a $\geq 5$ to $<10 \%$ relative decrease in FVC within 24 months [32]. Moreover, we also proposed that progressive ILD be defined as a disease showing a relative decline in FVC of $\geq 10 \%$ /year and/or that in DLCO of $\geq 7.5 \%$ /year, which may be useful in clinical decision- 
making when determining therapy for fibrotic NSIP [58]. We present a therapeutic strategy for RA-ILD based on this concept of PF-ILD as below.

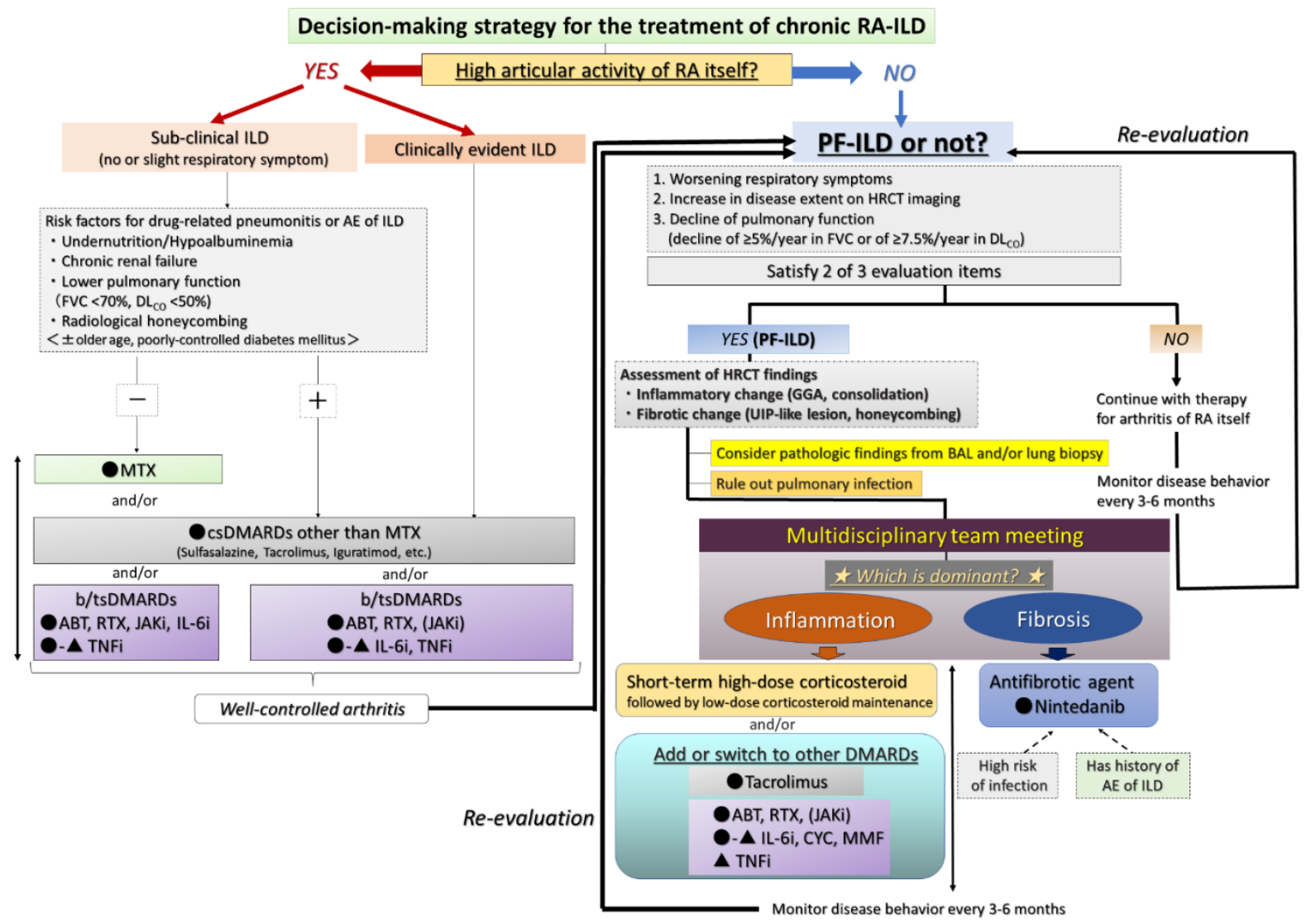

Figure 7. Proposed management algorithm for chronic RA-ILD. Abbreviations: ABT = abatacept; AE = acute exacerbation; $\mathrm{BAL}=$ bronchoalveolar lavage; $\mathrm{b} / \mathrm{tsDMARD}=$ biologic/targeted synthetic DMARD; csDMARD = conventional synthetic DMARD; DLCO = diffusing capacity for carbon monoxide; DMARD = disease-modifying anti-rheumatic drug; FVC = forced vital capacity; GGA = ground-glass attenuation; ILD = interstitial lung disease; JAKi = Janus kinase inhibitor; MTX = methotrexate; PF-ILD = progressive fibrosing ILD; RA = rheumatoid arthritis; RTX = rituximab; IL-6i = interluekin-6 inhibitor; $\mathrm{CYC}=$ cyclophosphamide; $\mathrm{MMF}=$ mycophenolate mofetil; $\mathrm{TNFi}=$ tumor necrosis factor-inhibitor; UIP = usual interstitial pneumonia.

\subsubsection{Presence of High Articular Activity of RA Itself Regardless of ILD Activity}

The arthritis activity of RA itself is one of the predictive factors of the development of RA-ILD [55]. In addition, higher activity of arthritis may be associated with the exacerbation of RA-ILD [56], and this can be a poor prognostic factor for patients with RA [5]. Therefore, if patients with RA-ILD suffer from symptoms of arthritis, arthritis should be treated first and then stabilized. Then, it can be determined whether the RA-ILD is sub-clinical ILD or clinically evident ILD (Figure 7).

Although the association between MTX and the pulmonary toxicity of ILD has been reported for some time, a recent report showed MTX use not to be associated with an increased risk of RA-ILD in patients with RA and that ILD was detected later in MTXtreated patients [59]. As one of the disease-modifying anti-rheumatic drugs (DMARDs), MTX is one of the most effective medications available to treat RA $[60,61]$. Thus, RA patients with sub-clinical ILD and no risk factors for drug-related pneumonitis or AE of ILD (e.g., undernutrition, chronic renal failure, reduced pulmonary function, or radiological honeycombing) should be treated with MTX without delay [55]. If the patient has any of the above risk factors or clinically evident ILD, the use of conventional synthetic DMARDs (csDMARDs) other than MTX (e.g., sulfasalazine, tacrolimus, or iguratimod) 
and/or biologic/targeted synthetic DMARDs (b/tsDMARD) should be considered [62]. In regard to the csDMARD leflunomide, because pre-existing ILD was the most important risk factor for the occurrence of leflunomide-induced ILD, we suggest that leflunomide not be prescribed for RA patients complicated by ILD [63]. Other csDMARDs such as sulfasalazine and tacrolimus are thought to provide some safety for the lung [57].

The safety of bDMARDs and tsDMARD and their effect on RA-ILD are not clear [62]. Although the possible effectiveness of bDMARDs in RA-ILD has been described in only a few retrospective studies and anecdotally, almost all of the bDMARDs have the possibility of improving and/or stabilizing lung function [57]. Therefore, therapeutic management should emphasize safety in regard to ILD [62]. Among the bDMARDs, ABT, TCZ, and RTX seem to be relatively safe for use in RA-ILD $[55,57,62,64]$. However, care must be taken with TCZ because some reports have shown it to be associated with the exacerbation of pre-existing RA-ILD, although TCZ demonstrated a potential effect on the stabilization of RA-ILD [65,66], and it prevents the progression of early systemic sclerosis-associated ILD [67]. Therefore, TCZ as an IL-6i may be effective for early or mild RA-ILD but should be avoided for clinically evident ILD or PF-ILD. Sarilumab is another IL-6i, but currently, there is no data on its efficacy in RA-ILD. In contrast, a recent review showed increased mortality with the use of tumor necrosis factor inhibitors (TNFi) in RA-ILD; therefore, TNFi may have lower priority in the treatment of RA-ILD [55,68]. Janus-kinase inhibitor (JAKi) as a tsDMARD was reported to cause a very low rate of ILD exacerbation [69,70]. Moreover, several reports have recently described the effectiveness of JAKi in fatal antimelanoma differentiation-associated protein 5 antibody-positive RP-ILD [71,72]. Although we cannot state this definitively, JAKi may provide additional benefit in the therapy of RAILD that is not limited just to that of the arthritis of RA. Taken together, clinicians should administer different DMARDs depending on their safety in RA-ILD and first stabilize the arthritis of RA itself without delay. Thereafter, the activity of ILD itself can become the treatment focus.

\subsubsection{Presence of Progressive ILD Itself despite Stable Arthritis}

As mentioned above, we judge whether the patient with RA-ILD has PF-ILD based on respiratory symptoms, disease extent on HRCT, and pulmonary function $[31,32,58]$. Even if the patients are thought not to have PF-ILD, their disease behavior is monitored every 3 to 6 months, and then we re-evaluate each time whether the patient has progressed to PF-ILD [73] (Figure 7). Needless to say, a multidisciplinary team meeting (including pulmonologist, rheumatologist, radiologist, and pathologist) is the preferred method for assessment for RA-ILD.

When we determine that a patient with RA-ILD has PF-ILD, we focus on the assessment of inflammatory or fibrotic changes in the HRCT findings. Inflammatory change is assumed when GGO and consolidation are present. As a caveat, GGO, which is a finding typically associated with inflammation or infiltration, does not always represent reversible lung disease, but rather in some cases, it may represent microscopic fibrosis [74], whereas fibrotic change is included in reticulation with traction bronchiectasis and honeycombing $[36,38,53]$. However, all etiologies associated with ILD can lead to a poor prognosis, particularly in cases in which a component of UIP is found to a certain degree $[53,58,73]$. In other words, some cases represent the natural evolution of the inflammatory change of ILD into a UIP pattern indicating fibrotic change [38,75]. In fact, we reported that a certain number of patients with RA-ILD developed honeycombing during long-term follow-up, regardless of whether they had UIP or NSIP, and that their median survival time was poor at 3.2 years after the formation of honeycombing [38]. Therefore, of importance when judging fibrotic change is whether UIP-like lesions (i.e., predominantly subpleural reticulation with traction bronchiectasis) and honeycombing have formed during the follow-up period. Although HRCT is considered the best tool in the evaluation of ILD, bronchoalveolar lavage and transbronchial lung biopsy may also be useful only when the possibility of combined pulmonary infection exists (Figure 8) or when it is difficult to judge which is the dominant 
condition, inflammation or fibrosis (Figure 9) [76]. However, because surgical lung biopsy was reportedly involved in a high rate of in-hospital deaths, it should be discouraged [77].

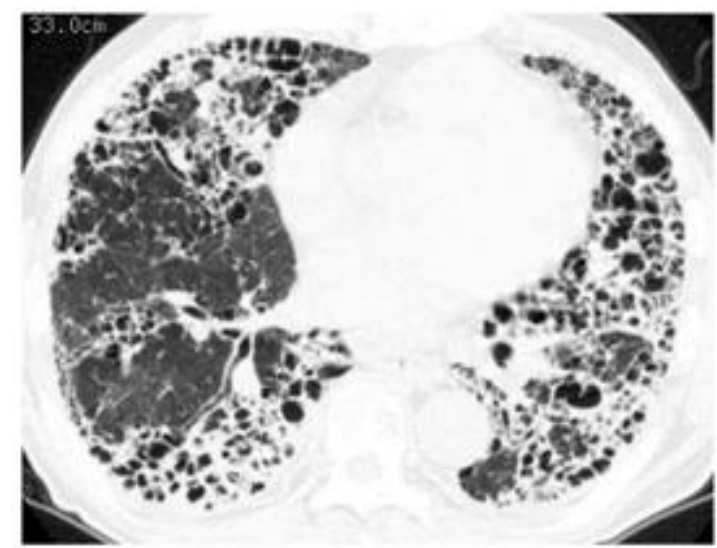

Figure 8. A case of RA-ILD in which the complication of nontuberculous mycobacterial pulmonary disease (Mycobacterium kansasii infection) developed. Chest computed tomography showed consolidation along with honeycombing.

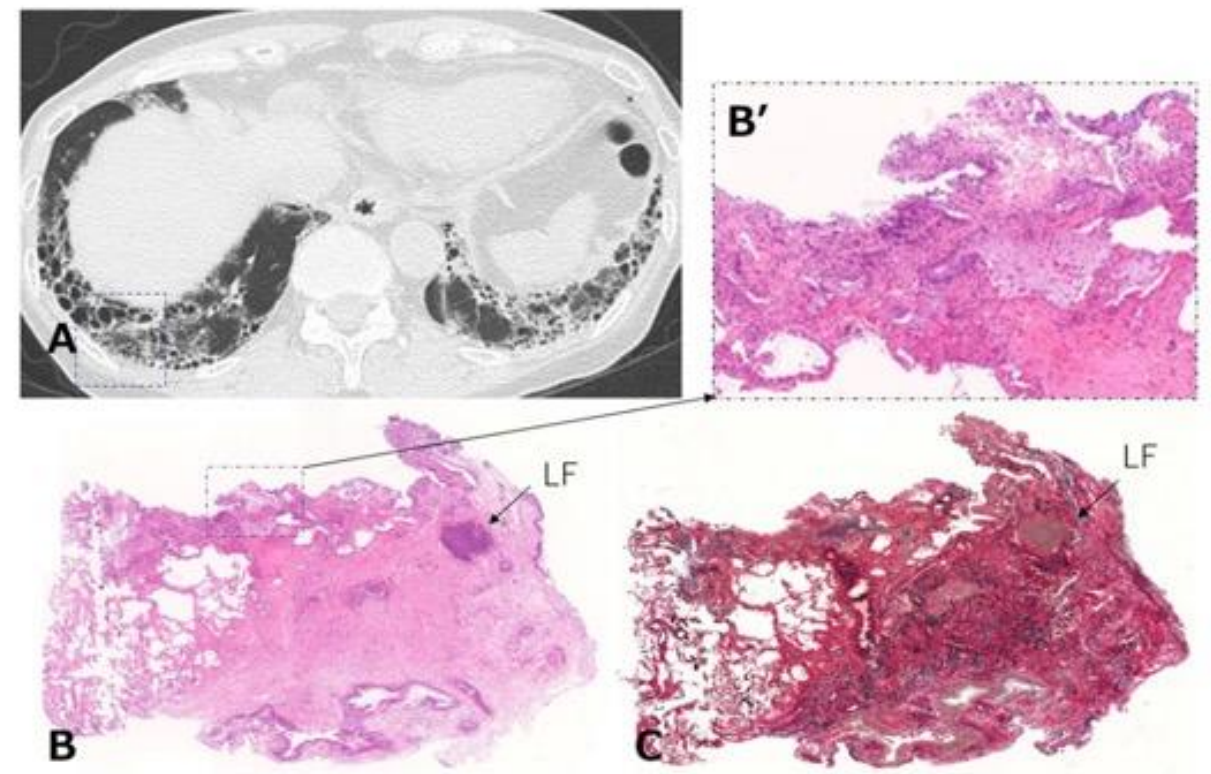

Figure 9. Transbronchial lung cryobiopsy in a case of RA-ILD (73-year-old woman). (A) Chest CT shows subpleural reticulations with honeycombing as the component of UIP in the lower lung. Lung cryobiopsy was performed in the right B9 (dashed square). (B) Hematoxylin and eosin staining show the lesion to be characterized by dense collagenous fibrosis with architectural destruction as a UIP pattern along with inflammatory cells including LF in the interstitial tissue. (B') A high-power magnification view of the dashed square in (B) shows a mild inflammatory change. (C) Elastica van Gieson staining shows the lesion as in (B). Abbreviations: RA = rheumatoid arthritis; ILD = interstitial lung disease; $\mathrm{CT}$ = computed tomography; UIP = usual interstitial pneumonia; $\mathrm{LF}=$ lymphoid follicle.

If we judge that inflammation is dominant in PF-ILD, we augment the basic RA therapy by strengthening the anti-inflammatory therapy. When administering anti-inflammatory therapy, we consider the use of a corticosteroid and/or adding or switching to other DMARDs. Yamano et al. reported that short-term high-dose corticosteroid followed by low-dose maintenance with tacrolimus significantly improved connective tissue diseaseassociated ILD including RA-ILD [78]. Some reports showed that corticosteroid improved or stabilized pulmonary function even if a UIP pattern was present $[22,37,78]$. As already 
mentioned, classification of specific HRCT patterns is often difficult, and RA-UIP frequently shows inflammatory pathologic change appearing as lymphoid hyperplasia unlike with IPF/UIP $[23,47,49]$. An example is shown in Figure 10, in which the patient had UIP-like lesions (i.e., predominant subpleural reticulation and honeycombing) indicative of RA-UIP. However, wall thickening of honeycombing resolved after high-dose corticosteroid therapy. Nevertheless, prednisolone doses higher than $10 \mathrm{mg}$ are associated with a high risk of infectious comorbidity [79]. Therefore, treatment with short-term high-dose corticosteroids followed by low-dose maintenance may be one effective therapy for RA-ILD including UIP. The efficacy of tacrolimus was also reported in myositis-associated ILD in addition to RA-ILD, and thus it might be another useful option $[78,80]$. As mentioned in the previous section, when keeping the safety of $\mathrm{b} / \mathrm{tsDMARDs}$ in mind, the first priority in treatment is ABT or RTX, followed by JAKi or TCZ and a TNFi. CYC and mycophenolate mofetil have a modest effect on systemic sclerosis-associated ILD [81,82], but there is little data on these drugs that indicate an effect on the clinical improvement and stability of RA-ILD [45,83].
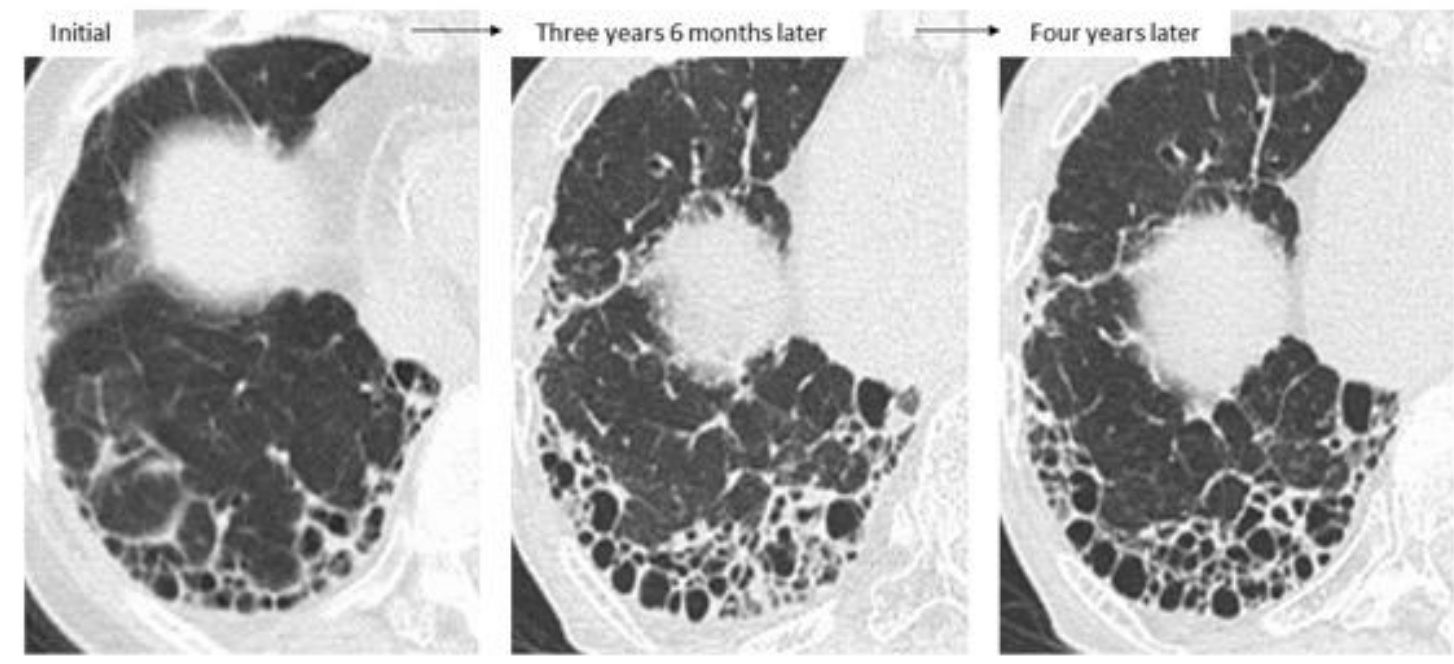

Figure 10. A patient who received sulfasalazine monotherapy for RA. Afterward, UIP-like lesions appearing as reticulations and honeycombing extended with worsening of the patient's respiratory symptoms, and wall thickening in the areas of honeycombing were also present at 3 years and 6 months after the initial image. After two courses of pulse dose methylprednisolone followed by low-dose prednisolone, wall thickening had improved by six months later.

If we determine that fibrosis is dominant in PF-ILD, we consider starting an antifibrotic agent such as nintedanib, which has been approved for the treatment of IPF in more than 70 countries and is effective and well-tolerated for the treatment of IPF [84,85]. Recently, the INBUILD study showed the effectiveness of nintedanib not only for IPF but PF-ILD including RA-ILD [31]. In patients who present with UIP-like lesions such as predominant subpleural reticulation and honeycombing seen on HRCT, lung function is known to worsen more quickly than that in patients presenting other patterns [53]. As shown in Figure 11, GGO around reticulations can improve with the administration of the antiinflammatory agent for arthritis itself, and after that, the UIP-like lesions become obvious along with the formation of honeycombing. Because prognosis after the formation of honeycombing is poor [38], if UIP-like lesions become obvious without inflammatory changes as indicated by GGO and wall thickening of honeycombing, early initiation of nintedanib should be considered. Interestingly, nintedanib might have the potential to suppress the AE of ILD [31], which is a most harmful event and can even be fatal [7,28,47]. Therefore, nintedanib is expected to be advantageous in the treatment of RA-ILD, and for patients with a history of AE of RA-ILD, priority intervention with nintedanib should be considered to help halt the progression to PF-ILD in RA. Moreover, particularly in cases in which it is difficult to judge whether inflammation or fibrosis is the dominant condition if a patient has factors predictive of a high risk of infection, nintedanib may be preferable to 
anti-inflammatory agents. Importantly, even though therapy such as an anti-inflammatory or anti-fibrotic agents is being administered, disease behavior should be monitored every 3-6 months to re-evaluate whether the RA-ILD remains under control.

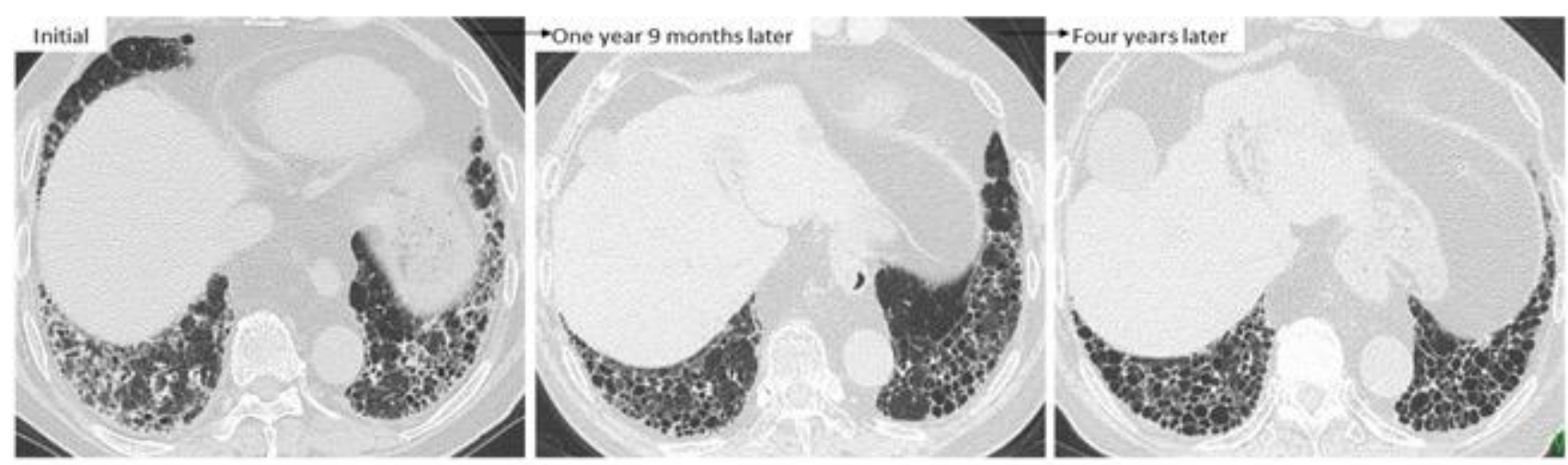

Figure 11. A case of RA-ILD showing ground-glass opacity around reticulations. This finding was improved at one year 9 months after treatment with anti-inflammatory agents such as tacrolimus and TNF inhibitor. However, UIP-like lesions (i.e., predominantly subpleural reticulation and honeycombing) without inflammatory change were obvious four years later.

\section{Conclusions}

RA-ILD can be divided into acute/subacute and chronic forms when considering therapeutic strategy. In the acute/subacute form, if the disease is severe as suggested by a DAD pattern, high-dose corticosteroids in combination with antimicrobial agents should be promptly initiated while considering the differential diagnosis, which is mainly AE of RA-ILD, drug-induced pneumonitis, or Pneumocystis pneumonia. In the chronic form of RA-ILD, the arthritis of RA itself should first be stabilized without delay, and afterward, the activity of ILD itself can be stabilized, considering the safety of each anti-rheumatic drug for use in RA-ILD. The formation or presence of UIP-like lesions can be related to progressive ILD, although HRCT can fail to identify specific patterns in actual practice. If inflammatory change is more dominant than fibrotic change, anti-inflammatory therapy should be strengthened. If fibrosis is dominant in patients with progressive RA-ILD and a high risk of infection or AE of ILD, clinicians should consider starting an antifibrotic agent. Prioritization of anti-inflammatory therapies or antifibrotic therapies will presumably remain an issue that must be solved in the context of individual diseases [53]. Thus, analysis of the HRCT findings is pivotal, and multidisciplinary discussion that includes the pulmonologist, rheumatologist, radiologist, and pathologist is needed to standardize the decision-making strategy for treatment that is necessary to correctly approach the diagnosis of patients with RA-ILD.

Author Contributions: Conceptualization, H.Y., T.O. and T.K.; methodology, T.O.; writing-original draft preparation, H.Y.; writing—review and editing, T.O., H.K., T.K., T.I., T.T. and K.K.; supervision, K.K.; project administration, H.Y. All authors have read and agreed to the published version of the manuscript.

Funding: This research did not receive any specific grant from any funding agencies in the public, commercial, or not-for-profit sectors.

Institutional Review Board Statement: Not applicable.

Informed Consent Statement: Not applicable.

Data Availability Statement: Not applicable. 
Conflicts of Interest: H.Y. and T.O. received honoraria from Nippon Boehringer Ingelheim Co., Ltd.; H.K. has received consulting fees, speaking fees, and/or honoraria from AbbVie G.K., Asahi Kasei Pharma, Astellas Pharma Inc., Bristol-Myers Squibb, Chugai Pharmaceutical Co. Ltd., Eisai Co. Ltd., Eli Lilly Japan K.K., Gilead Sciences, Janssen Pharmaceutical K.K., Mitsubishi Tanabe Pharma, Novartis Pharma K.K., and Sanofi Pharma and has received research grants from AbbVie G.K., Asahi Kasei Pharma, Astellas Pharma Inc., Chugai Pharmaceutical Co. Ltd., Eisai Co. Ltd., Mitsubishi Tanabe Pharma, Novartis Pharma K.K., and Sanofi Pharma. T.K., T.I., T.T., and K.K. have no conflicts of interest to declare.

\section{References}

1. Scott, D.L.; Wolfe, F.; Huizinga, T.W. Rheumatoid arthritis. Lancet 2010, 376, 1094-1108. [CrossRef]

2. Huang, S.; Kronzer, V.L.; Dellaripa, P.F.; Deane, K.D.; Bolster, M.B.; Nagaraja, V.; Khanna, D.; Doyle, T.J.; Sparks, J.A. Rheumatoid arthritis-associated interstitial lung disease: Current update on prevalence, risk factors, and pharmacologic treatment. Curr. Treat. Opt. Rheumatol. 2020, 6, 337-353. [CrossRef] [PubMed]

3. Nakajima, A.; Inoue, E.; Tanaka, E.; Singh, G.; Sato, E.; Hoshi, D.; Shidara, K.; Hara, M.; Momohara, S.; Taniguchi, A.; et al. Mortality and cause of death in Japanese patients with rheumatoid arthritis based on a large observational cohort, IORRA. Scand. J. Rheumatol. 2010, 39, 360-367. [CrossRef] [PubMed]

4. Koduri, G.; Norton, S.; Young, A.; Cox, N.; Davies, P.; Devlin, J.; Dixey, J.; Gough, A.; Prouse, P.; Winfield, J.; et al. Interstitial lung disease has a poor prognosis in rheumatoid arthritis: Results from an inception cohort. Rheumatology 2010, 49, 1483-1489. [CrossRef] [PubMed]

5. Kakutani, T.; Hashimoto, A.; Tominaga, A.; Kodama, K.; Nogi, S.; Tsuno, H.; Ogihara, H.; Nunokawa, T.; Komiya, A.; Furukawa, H.; et al. Related factors, increased mortality and causes of death in patients with rheumatoid arthritis-associated interstitial lung disease. Mod. Rheumatol. 2020, 30, 458-464. [CrossRef] [PubMed]

6. Gutsche, M.; Rosen, G.D.; Swigris, J.J. Connective tissue disease-associated interstitial lung disease: A review. Curr. Respir. Care Rep. 2012, 1, 224-232. [CrossRef]

7. Hozumi, H.; Nakamura, Y.; Johkoh, T.; Sumikawa, H.; Colby, T.V.; Kono, M.; Hashimoto, D.; Enomoto, N.; Fujisawa, T.; Inui, N.; et al. Acute exacerbation in rheumatoid arthritis-associated interstitial lung disease: A retrospective case control study. BMJ Open. 2013, 3, e003132. [CrossRef]

8. Barrera, P.; Laan, R.F.; van Riel, P.L.; Dekhuijzen, P.N.; Boerbooms, A.M.; van de Putte, L.B. Methotrexate-related pulmonary complications in rheumatoid arthritis. Ann. Rheum. Dis. 1994, 53, 434-439. [CrossRef]

9. Sakai, F.; Noma, S.; Kurihara, Y.; Yamada, H.; Azuma, A.; Kudoh, S.; Ichikawa, Y. Leflunomide-related lung injury in patients with rheumatoid arthritis: Imaging features. Mod. Rheumatol. 2005, 15, 173-179. [CrossRef]

10. Scott, D.L.; Bradby, G.V.; Aitman, T.J.; Zaphiropoulos, G.C.; Hawkins, C.F. Relationship of gold and penicillamine therapy to diffuse interstitial lung disease. Ann. Rheum. Dis. 1981, 40, 136-141. [CrossRef]

11. Parry, S.D.; Barbatzas, C.; Peel, E.T.; Barton, J.R. Sulphasalazine and lung toxicity. Eur. Respir. J. 2002, 19, 756-764. [CrossRef] [PubMed]

12. Kameda, H. DLI caused by disease-modifying antirheumatic drugs: What are the characteristics of DLI by disease-modifying antirheumatic drugs? In Drug-Induced Lung Injury; Hanaoka, M., Nakamura, H., Aoshiba, K., Eds.; Springer: Singapore, 2017; pp. 165-176.

13. Zisman, D.A.; McCune, W.J.; Tino, G.; Lynch, J.P., 3rd. Drug-induced pneumonitis: The role of methotrexate. Sarcoidosis Vasc. Diffus. Lung Dis. 2001, 18, 243-252.

14. Obadina, E.T.; Torrealba, J.M.; Kanne, J.P. Acute pulmonary injury: High-resolution CT and histopathological spectrum. Br. J. Radiol. 2013, 86, 20120614. [CrossRef]

15. Carmona, E.M.; Limper, A.H. Update on the diagnosis and treatment of Pneumocystis pneumonia. Ther. Adv. Respir. Dis. 2011, 5, 41-59. [CrossRef] [PubMed]

16. Saravanan, V.; Kelly, C.A. Reducing the risk of methotrexate pneumonitis in rheumatoid arthritis. Rheumatology 2004, 43, 143-147. [CrossRef]

17. Innabi, A.; Gomez-Manjarres, D.; Alzghoul, B.N.; Chizinga, M.; Mehrad, B.; Patel, D.C. Cyclophosphamide for the treatment of acute exacerbation of interstitial lung disease: A review of the literature. Sarcoidosis Vasc. Diffus. Lung Dis. 2021, 38 , e2021002.

18. Mohning, M.P.; Amigues, I.; Demoruelle, M.K.; Fernández Pérez, E.R.; Huie, T.J.; Keith, R.K.; Olson, A.L.; Yunt, Z.X.; Chung, J.H.; Hobbs, S.; et al. Duration of rheumatoid arthritis and the risk of developing interstitial lung disease. ERJ Open Res. $2021,7,633$. [CrossRef] [PubMed]

19. Doyle, T.J.; Lee, J.S.; Dellaripa, P.F.; Lederer, J.A.; Matteson, E.L.; Fischer, A.; Ascherman, D.P.; Glassberg, M.K.; Ryu, J.H.; Danoff, S.K.; et al. A roadmap to promote clinical and translational research in rheumatoid arthritis-associated interstitial lung disease. Chest 2014, 145, 454-463. [CrossRef]

20. Zamora-Legoff, J.A.; Krause, M.L.; Crowson, C.S.; Ryu, J.H.; Matteson, E.L. Patterns of interstitial lung disease and mortality in rheumatoid arthritis. Rheumatology 2017, 56, 344-350. [CrossRef] 
21. Kono, M.; Nakamura, Y.; Enomoto, N.; Hashimoto, D.; Fujisawa, T.; Inui, N.; Maekawa, M.; Suda, T.; Colby, T.V.; Chida, K. Usual interstitial pneumonia preceding collagen vascular disease: A retrospective case control study of patients initially diagnosed with idiopathic pulmonary fibrosis. PLoS ONE 2014, 9, e94775.

22. Lee, H.K.; Kim, D.S.; Yoo, B.; Seo, J.B.; Rho, J.Y.; Colby, T.V.; Kitaichi, M. Histopathologic pattern and clinical features of rheumatoid arthritis-associated interstitial lung disease. Chest 2005, 127, 2019-2027. [CrossRef]

23. Kim, E.J.; Elicker, B.M.; Maldonado, F.; Webb, W.R.; Ryu, J.H.; Van Uden, J.H.; Lee, J.S.; King, T.E., Jr.; Collard, H.R. Usual interstitial pneumonia in rheumatoid arthritis-associated interstitial lung disease. Eur. Respir. J. 2010, 35, 1322-1328. [CrossRef]

24. Assayag, D.; Lee, J.S.; King, T.E., Jr. Rheumatoid arthritis associated interstitial lung disease: A review. Medicina 2014, 74, 158-165. [PubMed]

25. Kelly, C.A.; Saravanan, V.; Nisar, M.; Arthanari, S.; Woodhead, F.A.; Price-Forbes, A.N.; Dawson, J.; Sathi, N.; Ahmad, Y.; Koduri, G.; et al. Rheumatoid arthritis-related interstitial lung disease: Associations, prognostic factors and physiological and radiological characteristics-A large multicentre UK study. Rheumatology 2014, 53, 1676-1682. [CrossRef] [PubMed]

26. Solomon, J.J.; Chung, J.H.; Cosgrove, G.P.; Demoruelle, M.K.; Fernandez-Perez, E.R.; Fischer, A.; Frankel, S.K.; Hobbs, S.B.; Huie, T.J.; Ketzer, J.; et al. Predictors of mortality in rheumatoid arthritis-associated interstitial lung disease. Eur. Respir. J. 2016, 47, 588-596. [CrossRef] [PubMed]

27. Natalini, J.G.; Swigris, J.J.; Morisset, J.; Elicker, B.M.; Jones, K.D.; Fischer, A.; Collard, H.R.; Lee, J.S. Understanding the determinants of health-related quality of life in rheumatoid arthritis-associated interstitial lung disease. Respir. Med. 2017, 127, 1-6. [CrossRef]

28. Suda, T. Up-to-date information on rheumatoid arthritis-associated interstitial lung disease. Clin. Med. Insights Circ. Respir. Pulm. Med. 2016, 9 (Suppl. S1), 155-162. [CrossRef] [PubMed]

29. Zamora-Legoff, J.A.; Krause, M.L.; Crowson, C.S.; Ryu, J.H.; Matteson, E.L. Progressive decline of lung function in rheumatoid arthritis-associated interstitial lung disease. Arthritis Rheumatol. 2017, 69, 542-549. [CrossRef] [PubMed]

30. Mena-Vázquez, N.; Rojas-Gimenez, M.; Romero-Barco, C.M.; Manrique-Arija, S.; Francisco, E.; Aguilar-Hurtado, M.C.; AñónOñate, I.; Pérez-Albaladejo, L.; Ortega-Castro, R.; Godoy-Navarrete, F.J.; et al. Predictors of progression and mortality in patients with prevalent rheumatoid arthritis and interstitial lung disease: A prospective cohort study. J. Clin. Med. 2021, 10, 874. [CrossRef]

31. Flaherty, K.R.; Wells, A.U.; Cottin, V.; Devaraj, A.; Walsh, S.L.F.; Inoue, Y.; Richeldi, L.; Kolb, M.; Tetzlaff, K.; Stowasser, S.; et al. Nintedanib in progressive fibrosing interstitial lung diseases. N. Engl. J. Med. 2019, 381, 1718-1727. [CrossRef]

32. Cottin, V.; Hirani, N.A.; Hotchkin, D.L.; Nambiar, A.M.; Ogura, T.; Otaola, M.; Skowasch, D.; Park, J.S.; Poonyagariyagorn, H.K.; Wuyts, W.; et al. Presentation, diagnosis and clinical course of the spectrum of progressive-fibrosing interstitial lung diseases. Eur. Respir. Rev. 2018, 27, 180076. [CrossRef]

33. Moua, T.; Zamora Martinez, A.C.; Baqir, M.; Vassallo, R.; Limper, A.H.; Ryu, J.H. Predictors of diagnosis and survival in idiopathic pulmonary fibrosis and connective tissue disease-related usual interstitial pneumonia. Respir. Res. 2014, 15, 154. [CrossRef] [PubMed]

34. Dawson, J.K.; Fewins, H.E.; Desmond, J.; Lynch, M.P.; Graham, D.R. Predictors of progression of HRCT diagnosed fibrosing alveolitis in patients with rheumatoid arthritis. Ann. Rheum. Dis. 2002, 61, 517-521. [CrossRef] [PubMed]

35. Park, J.H.; Kim, D.S.; Park, I.N.; Jang, S.J.; Kitaichi, M.; Nicholson, A.G.; Colby, T.V. Prognosis of fibrotic interstitial pneumonia: Idiopathic versus collagen vascular disease-related subtypes. Am. J. Respir. Crit. Care Med. 2007, 175, 705-711. [CrossRef]

36. Adegunsoye, A.; Oldham, J.M.; Bellam, S.K.; Montner, S.; Churpek, M.M.; Noth, I.; Vij, R.; Strek, M.E.; Chung, J.H. Computed tomography honeycombing identifies a progressive fibrotic phenotype with increased mortality across diverse interstitial lung diseases. Ann. Am. Thorac. Soc. 2019, 16, 580-588. [CrossRef] [PubMed]

37. Song, J.W.; Lee, H.K.; Lee, C.K.; Chae, E.J.; Jang, S.J.; Colby, T.V.; Kim, D.S. Clinical course and outcome of rheumatoid arthritis-related usual interstitial pneumonia. Sarcoidosis Vasc. Diffus. Lung Dis. 2013, 30, 103-112.

38. Yamakawa, H.; Sato, S.; Nishizawa, T.; Kawabe, R.; Oba, T.; Kato, A.; Horikoshi, M.; Akasaka, K.; Amano, M.; Sasaki, H.; et al. Impact of radiological honeycombing in rheumatoid arthritis-associated interstitial lung disease. BMC Pulm. Med. 2020, 20, 25. [CrossRef]

39. Bongartz, T.; Nannini, C.; Medina-Velasquez, Y.F.; Achenbach, S.J.; Crowson, C.S.; Ryu, J.H.; Vassallo, R.; Gabriel, S.E.; Matteson, E.L. Incidence and mortality of interstitial lung disease in rheumatoid arthritis: A population-based study. Arthritis Rheum. 2010, 62, 1583-1591. [CrossRef] [PubMed]

40. Juge, P.A.; Lee, J.S.; Ebstein, E.; Furukawa, H.; Dobrinskikh, E.; Gazal, S.; Kannengiesser, C.; Ottaviani, S.; Oka, S.; Tohma, S.; et al. MUC5B Promoter variant and rheumatoid arthritis with interstitial lung disease. N. Engl. J. Med. 2018, 379, 2209-2219. [CrossRef]

41. Newton, C.A.; Oldham, J.M.; Ley, B.; Anand, V.; Adegunsoye, A.; Liu, G.; Batra, K.; Torrealba, J.; Kozlitina, J.; Glazer, C.; et al. Telomere length and genetic variant associations with interstitial lung disease progression and survival. Eur. Respir. J. 2019, 53, 1801641. [CrossRef]

42. Tsuchiya, Y.; Takayanagi, N.; Sugiura, H.; Miyahara, Y.; Tokunaga, D.; Kawabata, Y.; Sugita, Y. Lung diseases directly associated with rheumatoid arthritis and their relationship to outcome. Eur. Respir. J. 2011, 37, 1411-1417. [CrossRef]

43. Morisset, J.; Vittinghoff, E.; Lee, B.Y.; Tonelli, R.; Hu, X.; Elicker, B.M.; Ryu, J.H.; Jones, K.D.; Cerri, S.; Manfredi, A.; et al. The performance of the GAP model in patients with rheumatoid arthritis associated interstitial lung disease. Respir. Med. 2017, 127, 51-56. [CrossRef] 
44. Yunt, Z.X.; Chung, J.H.; Hobbs, S.; Fernandez-Perez, E.R.; Olson, A.L.; Huie, T.J.; Keith, R.C.; Janssen, W.J.; Goldstein, B.L.; Lynch, D.A.; et al. High resolution computed tomography pattern of usual interstitial pneumonia in rheumatoid arthritis-associated interstitial lung disease: Relationship to survival. Respir. Med. 2017, 126, 100-104. [CrossRef] [PubMed]

45. Fu, Q.; Wang, L.; Li, L.; Li, Y.; Liu, R.; Zheng, Y. Risk factors for progression and prognosis of rheumatoid arthritis-associated interstitial lung disease: Single center study with a large sample of Chinese population. Clin. Rheumatol. 2019, 38, 1109-1116. [CrossRef] [PubMed]

46. Jacob, J.; Hirani, N.; van Moorsel, C.H.M.; Rajagopalan, S.; Murchison, J.T.; van Es, H.W.; Bartholmai, B.J.; van Beek, F.T.; Struik, M.H.L.; Stewart, G.A.; et al. Predicting outcomes in rheumatoid arthritis related interstitial lung disease. Eur. Respir. J. 2019, 53, 1800869. [CrossRef]

47. Yamakawa, H.; Sato, S.; Tsumiyama, E.; Nishizawa, T.; Kawabe, R.; Oba, T.; Kamikawa, T.; Horikoshi, M.; Akasaka, K.; Amano, M.; et al. Predictive factors of mortality in rheumatoid arthritis-associated interstitial lung disease analysed by modified HRCT classification of idiopathic pulmonary fibrosis according to the 2018 ATS/ERS/JRS/ALAT criteria. J. Thorac. Dis. 2019, 11, 5247-5257. [CrossRef] [PubMed]

48. Nurmi, H.; Kaarteenaho, R. The challenges in classifying rheumatoid arthritis-associated interstitial lung disease. J. Thorac. Dis. 2020, 12, 3000-3003. [CrossRef] [PubMed]

49. Smith, M.; Dalurzo, M.; Panse, P.; Parish, J.; Leslie, K. Usual interstitial pneumonia-pattern fibrosis in surgical lung biopsies. Clinical, radiological and histopathological clues to aetiology. J. Clin. Pathol. 2013, 66, 896-903. [CrossRef]

50. Shidara, K.; Hoshi, D.; Inoue, E.; Yamada, T.; Nakajima, A.; Taniguchi, A.; Hara, M.; Momohara, S.; Kamatani, N.; Yamanaka, H. Incidence of and risk factors for interstitial pneumonia in patients with rheumatoid arthritis in a large Japanese observational cohort, IORRA. Mod. Rheumatol. 2010, 20, 280-286. [CrossRef]

51. Natsuizaka, M.; Chiba, H.; Kuronuma, K.; Otsuka, M.; Kudo, K.; Mori, M.; Bando, M.; Sugiyama, Y.; Takahashi, H. Epidemiologic survey of Japanese patients with idiopathic pulmonary fibrosis and investigation of ethnic differences. Am. J. Respir. Crit. Care Med. 2014, 190, 773-779. [CrossRef]

52. Jeon, K.; Chung, M.P.; Lee, K.S.; Chung, M.J.; Han, J.; Koh, W.J.; Suh, G.Y.; Kim, H.; Kwon, O.J. Prognostic factors and causes of death in Korean patients with idiopathic pulmonary fibrosis. Respir. Med. 2006, 100, 451-457. [CrossRef]

53. Makino, S. Progressive fibrosing interstitial lung diseases: A new concept and indication of nintedanib. Mod. Rheumatol. 2021, 31, 13-19. [CrossRef]

54. Faverio, P.; Kalluri, M.; Luppi, F.; Ferrara, G. RA-ILD: Does more detailed radiological classification add something to our knowledge of this condition? J. Thorac. Dis. 2020, 12, 2993-2995. [CrossRef] [PubMed]

55. Fragoulis, G.E.; Nikiphorou, E.; Larsen, J.; Korsten, P.; Conway, R. Methotrexate-associated pneumonitis and rheumatoid arthritis-interstitial lung disease: Current concepts for the diagnosis and treatment. Front. Med. 2019, 6, 238. [CrossRef]

56. Akiyama, M.; Kaneko, Y.; Yamaoka, K.; Kondo, H.; Takeuchi, T. Association of disease activity with acute exacerbation of interstitial lung disease during tocilizumab treatment in patients with rheumatoid arthritis: A retrospective, case-control study. Rheumatol. Int. 2016, 36, 881-889. [CrossRef] [PubMed]

57. Cassone, G.; Manfredi, A.; Vacchi, C.; Luppi, F.; Coppi, F.; Salvarani, C.; Sebastiani, M. Treatment of rheumatoid arthritis-associated interstitial lung disease: Lights and shadows. J. Clin. Med. 2020, 9, 1082. [CrossRef] [PubMed]

58. Yamakawa, H.; Kitamura, H.; Takemura, T.; Ikeda, S.; Sekine, A.; Baba, T.; Iwasawa, T.; Hagiwara, E.; Sato, S.; Ogura, T. Prognostic factors and disease behaviour of pathologically proven fibrotic non-specific interstitial pneumonia. Respirology 2018, 23, 1032-1040. [CrossRef] [PubMed]

59. Juge, P.A.; Lee, J.S.; Lau, J.; Kawano-Dourado, L.; Rojas Serrano, J.; Sebastiani, M.; Koduri, G.; Matteson, E.; Bonfiglioli, K.; Sawamura, M.; et al. Methotrexate and rheumatoid arthritis associated interstitial lung disease. Eur. Respir. J. 2021, 57, 2000337. [CrossRef]

60. Salliot, C.; van der Heijde, D. Long-term safety of methotrexate monotherapy in patients with rheumatoid arthritis: A systematic literature research. Ann. Rheum. Dis. 2009, 68, 1100-1104. [CrossRef]

61. Kameda, H.; Fujii, T.; Nakajima, A.; Koike, R.; Sagawa, A.; Kanbe, K.; Tomita, T.; Harigai, M.; Suzuki, Y. Japan College of Rheumatology subcommittee on the guideline for the use of methotrexate in patients with rheumatoid arthritis. Mod. Rheumatol. 2019, 29, 31-40. [CrossRef]

62. Holroyd, C.R.; Seth, R.; Bukhari, M.; Malaviya, A.; Holmes, C.; Curtis, E.; Chan, C.; Yusuf, M.A.; Litwic, A.; Smolen, S.; et al. The British Society for Rheumatology biologic DMARD safety guidelines in inflammatory arthritis. Rheumatology 2019, 58, e3-e42. [CrossRef]

63. Raj, R.; Nugent, K. Leflunomide-induced interstitial lung disease (a systematic review). Sarcoidosis Vasc. Diffus. Lung Dis. 2013, 30, 167-176.

64. Vicente-Rabaneda, E.F.; Atienza-Mateo, B.; Blanco, R.; Cavagna, L.; Ancochea, J.; Castañeda, S.; González-Gay, M.Á. Efficacy and safety of abatacept in interstitial lung disease of rheumatoid arthritis: A systematic literature review. Autoimmun. Rev. 2021, 20, 102830. [CrossRef]

65. Manfredi, A.; Cassone, G.; Furini, F.; Gremese, E.; Venerito, V.; Atzeni, F.; Arrigoni, E.; Della Casa, G.; Cerri, S.; Govoni, M.; et al. Tocilizumab therapy in rheumatoid arthritis with interstitial lung disease: A multicentre retrospective study. Intern. Med. J. 2020, 50, 1085-1090. [CrossRef] 
66. Koike, T.; Harigai, M.; Inokuma, S.; Ishiguro, N.; Ryu, J.; Takeuchi, T.; Takei, S.; Tanaka, Y.; Ito, K.; Yamanaka, H. Postmarketing surveillance of tocilizumab for rheumatoid arthritis in Japan: Interim analysis of 3881 patients. Ann. Rheum. Dis. 2011, 70, 2148-2151. [CrossRef] [PubMed]

67. Roofeh, D.; Lin, C.J.F.; Goldin, J.; Kim, G.H.; Furst, D.E.; Denton, C.P.; Huang, S.; Khanna, D.; focuSSced Investigators. Tocilizumab prevents progression of early systemic sclerosis associated interstitial lung disease. Arthritis Rheumatol. 2021, 7, 1301-1310. [CrossRef] [PubMed]

68. Huang, Y.; Lin, W.; Chen, Z.; Wang, Y.; Huang, Y.; Tu, S. Effect of tumor necrosis factor inhibitors on interstitial lung disease in rheumatoid arthritis: Angel or demon? Drug Des. Dev. Ther. 2019, 13, 2111-2125. [CrossRef]

69. Fleischmann, R.; Wollenhaupt, J.; Takiya, L.; Maniccia, A.; Kwok, K.; Wang, L.; van Vollenhoven, R.F. Safety and maintenance of response for tofacitinib monotherapy and combination therapy in rheumatoid arthritis: An analysis of pooled data from open-label long-term extension studies. RMD Open. 2017, 3, e000491. [CrossRef]

70. Cohen, S.; Radominski, S.C.; Gomez-Reino, J.J.; Wang, L.; Krishnaswami, S.; Wood, S.P.; Soma, K.; Nduaka, C.I.; Kwok, K.; Valdez, $\mathrm{H}$; ; et al. Analysis of infections and all-cause mortality in phase II, phase III, and long-term extension studies of tofacitinib in patients with rheumatoid arthritis. Arthritis Rheumatol. 2014, 66, 2924-2937. [CrossRef]

71. Kurasawa, K.; Arai, S.; Namiki, Y.; Tanaka, A.; Takamura, Y.; Owada, T.; Arima, M.; Maezawa, R. Tofacitinib for refractory interstitial lung diseases in anti-melanoma differentiation-associated 5 gene antibody-positive dermatomyositis. Rheumatology 2018, 57, 2114-2119. [CrossRef]

72. Chen, Z.; Wang, X.; Ye, S. Tofacitinib in amyopathic dermatomyositis-associated interstitial lung disease. N. Engl. J. Med. 2019, 381, 291-293. [CrossRef]

73. Gibson, C.D.; Kugler, M.C.; Deshwal, H.; Munger, J.S.; Condos, R. Advances in targeted therapy for progressive fibrosing interstitial lung disease. Lung 2020, 198, 597-608. [CrossRef]

74. Elicker, B.M.; Kallianos, K.G.; Henry, T.S. The role of high-resolution computed tomography in the follow-up of diffuse lung disease: Number 2 in the Series "Radiology" Edited by Nicola Sverzellati and Sujal Desai. Eur. Respir. Rev. 2017, 26, 170008. [CrossRef]

75. Silva, C.I.; Müller, N.L.; Hansell, D.M.; Lee, K.S.; Nicholson, A.G.; Wells, A.U. Nonspecific interstitial pneumonia and idiopathic pulmonary fibrosis: Changes in pattern and distribution of disease over time. Radiology 2008, 247, 251-259. [CrossRef]

76. Bulpa, P.A.; Dive, A.M.; Mertens, L.; Delos, M.A.; Jamart, J.; Evrard, P.A.; Gonzalez, M.R.; Installé, E.J. Combined bronchoalveolar lavage and transbronchial lung biopsy: Safety and yield in ventilated patients. Eur. Respir. J. 2003, 21, 489-494. [CrossRef]

77. Caples, S.M.; Utz, J.P.; Allen, M.S.; Ryu, J.H. Thoracic surgical procedures in patients with rheumatoid arthritis. J. Rheumatol. 2004, 31, 2136-2141. [PubMed]

78. Yamano, Y.; Taniguchi, H.; Kondoh, Y.; Ando, M.; Kataoka, K.; Furukawa, T.; Johkoh, T.; Fukuoka, J.; Sakamoto, K.; Hasegawa, Y. Multidimensional improvement in connective tissue disease-associated interstitial lung disease: Two courses of pulse dose methylprednisolone followed by low-dose prednisone and tacrolimus. Respirology 2018, 23, 1041-1048. [CrossRef]

79. Zamora-Legoff, J.A.; Krause, M.L.; Crowson, C.S.; Ryu, J.H.; Matteson, E.L. Risk of serious infection in patients with rheumatoid arthritis-associated interstitial lung disease. Clin. Rheumatol. 2016, 35, 2585-2589. [CrossRef] [PubMed]

80. Fujisawa, T.; Hozumi, H.; Kamiya, Y.; Kaida, Y.; Akamatsu, T.; Kusagaya, H.; Satake, Y.; Mori, K.; Mikamo, M.; Matsuda, H.; et al. Prednisolone and tacrolimus versus prednisolone and cyclosporin A to treat polymyositis/dermatomyositis-associated ILD: A randomized, open-label trial. Respirology 2021, 26, 370-377. [CrossRef] [PubMed]

81. Tashkin, D.P.; Elashoff, R.; Clements, P.J.; Roth, M.D.; Furst, D.E.; Silver, R.M.; Goldin, J.; Arriola, E.; Strange, C.; Bolster, M.B.; et al. Effects of 1-year treatment with cyclophosphamide on outcomes at 2 years in scleroderma lung disease. Am. J. Respir. Crit. Care Med. 2007, 176, 1026-1034. [CrossRef]

82. Swigris, J.J.; Olson, A.L.; Fischer, A.; Lynch, D.A.; Cosgrove, G.P.; Frankel, S.K.; Meehan, R.T.; Brown, K.K. Mycophenolate mofetil is safe, well tolerated, and preserves lung function in patients with connective tissue disease-related interstitial lung disease. Chest 2006, 130, 30-36. [CrossRef]

83. Saketkoo, L.A.; Espinoza, L.R. Rheumatoid arthritis interstitial lung disease: Mycophenolate mofetil as an antifibrotic and disease-modifying antirheumatic drug. Arch. Intern. Med. 2008, 168, 1718-1719. [PubMed]

84. Richeldi, L.; du Bois, R.M.; Raghu, G.; Azuma, A.; Brown, K.K.; Costabel, U.; Cottin, V.; Flaherty, K.R.; Hansell, D.M.; Inoue, Y.; et al. Efficacy and safety of nintedanib in idiopathic pulmonary fibrosis. N. Engl. J. Med. 2014, 370, 2071-2082. [CrossRef] [PubMed]

85. Fletcher, S.V.; Jones, M.G.; Renzoni, E.A.; Parfrey, H.; Hoyles, R.K.; Spinks, K.; Kokosi, M.; Kwok, A.; Warburton, C.; Titmuss, V.; et al. Safety and tolerability of nintedanib for the treatment of idiopathic pulmonary fibrosis in routine UK clinical practice. ERJ Open Res. 2018, 4, 49. [CrossRef] [PubMed] 